\title{
Acceptability and awareness of intrauterine contraceptive device among reproductive age women
}

\author{
S. Ramkumar ${ }^{1}$, S. Vijayalakshmi ${ }^{2}$, R. Soundararajan ${ }^{1 *}$, M. Elakkiyachelvi ${ }^{1}$, \\ E. Elakkiya ${ }^{1}$, S. Fathima ${ }^{1}$
}

\begin{abstract}
${ }^{1}$ Department of Community Medicine Dhanalakshmi Srinivasan Medical College and Hospital, Siruvachur, Perambalur, Tamil Nadu, India

${ }^{2}$ Department of Community Medicine, Sri Venkateswara Medical College and Hospital, Pondicherry, India
\end{abstract}

Received: 21 July 2021

Accepted: 20 August 2021

\section{*Correspondence:}

Dr. R. Soundararajan,

E-mail: drsoundarspm@gmail.com

Copyright: (c) the author(s), publisher and licensee Medip Academy. This is an open-access article distributed under the terms of the Creative Commons Attribution Non-Commercial License, which permits unrestricted non-commercial use, distribution, and reproduction in any medium, provided the original work is properly cited.

\section{ABSTRACT}

Contraception is the intentional prevention of conception through the use of various devices, sexual practices, chemicals, drugs or surgical procedures. An effective contraception allows a physical relationship without fear of an unwanted pregnancy and ensures freedom to have children when desired. In this article we are going to see their utilization and awareness about usage of intrauterine contraceptive device (IUCD).

Keywords: IUCD, Contraception, Sexual practices

\section{INTRODUCTION}

India is second most populous country in word and first 1 to introduce family planning services. ${ }^{1}$ By definition contraceptive methods were to prevent unwanted pregnancies either temporary or by permanent means. $^{2}$

Certain studies states that conceiving within 2 years of delivery counts to certain adverse effects contributing to maternal and neonatal mortality such as postpartum haemorrhage.

Globally there are 1.9 billion women who are child bearing age group (15-49 years) as per 2019 data, in that group 1.1 billion women are in need for family planning; among those women, 842 million are already using contraceptives, and unmet needs for contraception about 270 million. $^{3}$

\section{FACTORS DETERMINING IUD USAGE}

Intrauterine contraceptive device: The intrauterine contraceptive devices (IUCD) is the only family planning method for couples requesting highly effective, reliable, inexpensive, non-hormonal, immediately reversible, and long-acting contraceptive method. ${ }^{4}$

The intrauterine contraceptive methods are top tier contraceptives as they are long-lasting, convenient, wellliked by users, cost-effective, unobtrusive, reversible, and have failure rates less than $1 \%$ per year for perfect and typical use, rivalling the efficacy of permanent tubal sterilization. $^{2}$

\section{Types of IUCD's}

$1^{\text {st }}$ generation IUCD: Lippes loop, $2^{\text {nd }}$ generation IUCD (Copper containing): Cu-T-200B, Cu-T-380A, Cu-T220C and Nova $\mathrm{T}$ and $3^{\text {rd }}$ generation IUCD: Mirena, Progestasert.

\section{Time of insertion}

The IUCD can be inserted at any time except during pregnancy, the most ideal time of insertion is during menstrual cycle or within 10 days of last menstrual period because the diameter of cervical canal is greater at this 
time than during the secretory phase. ${ }^{5}$ The uterus is relaxed and the expulsion rate is minimum.

\section{Immediate postpartum insertion}

Here it means that inserting IUD during the $1^{\text {st }}$ weeks of delivery before the women leaves the hospital. ${ }^{6}$

\section{PPIUCD}

It is method of preventing unintended, unwanted and closely spaced pregnancies in the first 12 months following delivery.

It will promote the health of the women and children by preventing psychological, obstetric, financial and other health-related complications. It is easy and safe and do not need repeated health care visits for delayed postpartum and interval insertion of the intrauterine contraceptive device.

\section{Intracesarian IUCD}

Termination of an unplanned pregnancy in patients with previous caesarean is dangerous. The rate of IUCD usage exceeds other hormonal method of contraception.

Retention rate of Intra-caesarean IUCD was higher than other routes of PPIUCD insertion. ${ }^{8}$ So, all those women now leave the hospital with a contraceptive in place, so they no need to come back for IUCD insertion at later.

Female literacy level, socio-economic status and they can come from any area either rural or urban which will not affect the acceptability and utilization of intra-caesarean IUCD insertion.

\section{Post-puerperal insertion}

Post puerperal insertion defines the IUD insertion within 6-8 weeks of delivery and it is the most convenient method.

\section{IUD follow up}

The major objectives were to provide the emotional and motivational support for the women and to confirm the presence of IUD in situ.

To diagnose and treat any side effects and complications as soon as possible.

\section{The role of IUD wearers}

They should regularly check the threads, if they fail to locate, they should consult the physicians. ${ }^{9}$ Similarly, when there are any missed periods or any side effects such as fever, pelvic pain, bleeding they consult the doctors.

\section{Mechanism of action of IUDS}

Inhibits fertilisation, Alters the biochemical environment of cervical mucus thus inhibiting sperm activation.

Thickens cervical mucus and decreases cervical mortality and creates foreign body reaction thereby inhibit implantation.

\section{Failure rate of IUDS}

IUDS has the lowest fertility rate and has the failure rate of $0.5-1.5 .^{3}$

\section{Adverse effect of IUD}

The adverse effects can be-Pain which is the most common cause of IUD removal, bleeding which is more with $1^{\text {st }}$ generation than $2^{\text {nd }}$ and $3^{\text {rd }}$ generation, pelvic inflammatory disease. ${ }^{10}$

Ectopic pregnancy which is more noticed with hormonal contraceptives, perforation of the organ is the most dangerous side effect noticed with IUDs, expulsion of IUDs and pregnancy with IUD in situ. ${ }^{11}$

\section{Contraindications of IUDS}

\section{Absolute contraindications}

In this the pregnancy, undiagnosed vaginal bleeding, pelvic inflammatory disease, genital tract carcinoma and previous ectopic pregnancy can be affected.

\section{Relative contraindications}

It includes-Previous history of pelvic inflammatory disease, congenital malformations, cervical discharge, anemia, menorrhagia and unmotivated females. ${ }^{10}$

\section{Family planning program}

India is the first country to start program for family planning in 1952 .

Government of India wants to increase the opportunity of utilization of services, by increasing institutional deliveries so the government of India is focussing on strengthening the post-partum family planning services.

$\mathrm{RMNCH}+\mathrm{A}$ counsellors are being appointed at all high case load facilities for counselling services. ${ }^{13}$

Fixed day static services in sterilization is made at facility level such as twice a week in district hospital to fortnightly once in block PHCs. ${ }^{13}$

Those who are undergoing sterilization, will be offered with compensation scheme by the central government 
ministry of health and family welfare, where they are providing compensation for loss of wages for the beneficiary and the health professionals.

Contraceptive services under the programme: Oral contraceptive pills (OCPs), ASHA will be delivering the OCP pills by door to door. OCP pills also will be available at the free of costs in all government health centers, condoms, free brand 'Nirodh' available at government facilities, IUCD, female sterilisation, male sterilisation and emergency contraceptive pills.

\section{Significance of family planning}

Greater investment in family planning helps to control the population growth by achieving the desired family size and reducing the illegal abortion thereby eliminating most of the death.

Certain studies shows that if the current unmet need for family planning is satisfied in the next 5 years we can prevent 35000 maternal death, 1.2 million infant death thereby reducing the maternal mortality and infant mortality rate and can save more than Rs 4,450 crores. ${ }^{13}$

By doing safe abortion service along with family planning service we can save Rs. 6,500 crores.

\section{Advantage of IUCD's over other contraceptive methods}

Inexpensive, usually it will be free from major side effects associated with hormonal pills, Simple method of insertion, IUCD kept for as long as needed and immediate reversal of reproduction once removed. ${ }^{14}$ Highest continuation rate and no need for continued motivation as for taking daily pills or using barrier methods consistently; only a single act of motivation is enough.

\section{Factors preventing the acceptance of IUCD in community}

In spite of its high efficacy the acceptance of IUCD is still a question. This may be due to any of the following factors like misconceptions and fear about complications of IUCDs, refusal of male partner, low levels of female education, unawareness about IUCD, religious beliefs, training of health care providers, improper availability of supplies to provide IUCD.

\section{CONCLUSION}

Contraception usages will enhance the human right of people to determine the number and spacing of their children.

Even though it sounds simple and effective method in preventing maternal mortality and promoting maternal health, still there is a lot of hesitation in accepting the IUCD in the community.
Since LSCS rate was increasing for various causes, women need efficacious long-term method for child spacing.

For the fertility rates to decline, to avoid unintended pregnancies and for preventing unsafe abortions and associated maternal and neonatal mortalities the use of contraceptives plays an important role.

However, IUCD use is also determined by supportive husbands/partners, literate status of the community, women's own perception of having the IUCD and the source of information about IUCD by mass media and their peers, relatives also play an essential role.

Proper husband's/partner's support is of critical importance because of its strong association with IUCD use. We should be very cautions while delivering the information related delivering IUCD related messages in the public mass-media.

Importance of IUCD should be educated to mothers during their pregnancy through counselling by health care workers government should also take steps to motivate the mothers via ASHAs, VHNs and by providing incentives for the health workers as well as the women to encourage family planning methods for population wellbeing and to create more awareness about benefits and importance of use if IUDS.

\section{Recommendations}

The family planning awareness can be thereby promoted by conducting awareness programmes, proper counselling during antenatal visits for the couples.

By providing proper training to health care workers in motivating reproductive age group peoples and communities. Empowering female education system will also improve the awareness regarding the family health

Therefore, the spread of the correct information regarding IUD usage is needed via mass media, campaigns and other voluntary organisation bodies were needed. Hence, all the measures to enhance utilization of IUCD should actively involve their respective partners.

The reassurance regarding the IUCD usage need to be dealt to the women and her partner and thereby counselling them to overcome the misinterpretation of use of IUDs.

\section{Funding: No funding sources Conflict of interest: None declared Ethical approval: Not required}

\section{REFERENCES}

1. Jairaj S, Dayyala S. A cross sectional study on acceptability and safety of IUCD among postpartum 
mothers at tertiary care hospital, Telangana. J Clin Diagnostic Res. 2016;10(1):LC01-6.

2. Kantorová V, Wheldon MC, Ueffing $\mathrm{P}$, Dasgupta ANZ. Estimating progress towards meeting women's contraceptive needs in 185 countries: A Bayesian hierarchical modelling study. PLoS Med. 2020;17(2):1-23.

3. World Health Organization. Family planning/Contraception. Fact Sheets; 2018. Available at: https://www.who.int/news-room/factsheets/detail/family-planning-contraception. Accessed November 22, 2018.

4. Gonie A, Worku C, Assefa T, Bogale D, Girma A. Acceptability and factors associated with postpartum IUCD use among women who gave birth at bale zone health facilities, Southeast-Ethiopia. Contracept Reprod Med. 2018;3(1):1-8.

5. Rusatira JC, Silberg C, Mickler A, Salmeron C, Twahirwa Rwema JO, Johnstone $\mathrm{M}$ et al. Family planning science and practice lessons from the 2018 International Conference on Family Planning. Gates Open Res. 2020;4.

6. Dereje N, Engida B, Holland RP. Factors associated with intrauterine contraceptive device use among women of reproductive age group in Addis Ababa, Ethiopia: A case control study. PLoS One. 2020;15(2):1-12.

7. Higgins JA, Smith NK. The Sexual Acceptability of Contraception: Reviewing the Literature and Building a New Concept. J Sex Res. 2016;53(45):417-56

8. Curtis KM, Tepper NK, Jatlaoui TC, Berry-Bibee E, Horton LG, Zapata LB et al. U.S. medical eligibility criteria for contraceptive use, 2016. MMWR Recomm Rep. 2016;65(3):1-104.

9. Photo U, Park K. Family Planning and the 2030 Agenda for Sustainable Development Data Booklet. 2011 [cited 2021 Sep 23]; Available from: http://creativecommons.

10. Brown W, Druce N, Bunting J, Radloff S, Koroma D, Gupta S et al. Developing the " 120 by 20 " goal for the global FP2020 initiative. Stud Fam Plann. 2014;45(1):73-84.

11. Indranil S, Roy RN. Mahajan and Gupta's Textbook of preventive and social medicine. 2013.

12. Park K. Park's Textbook of preventive and social medicine, $23^{\text {rd }}$ edi. 2015;1-989.

13. Thapa S, Paudel IS, Bhattarai S, Joshi R, Thapa K. Factors affecting IUCD discontinuation in Nepal: A nested case-control study. Asia-Pacific J Public Heal. 2015;27(2):NP1280-7.

14. Dong J, Wang Y, Yu L, Zhang P, Liu X, Zhang L et al. Pathogenicity of a newly emerged recombined porcine reproductive and respiratory syndrome virus strain (subgenotype III) in China. Vet Microbiol. 2017;210:162-6.

15. Goswami D, Ravi AK, Sharma A. Missing IUCD Strings: Role of Imaging in Locating the Misplaced Device. J Clin Diagn Res. 2017;11(4): QJ01-2.

Cite this article as: Ramkumar S, Vijayalakshmi S, Soundararajan R, Elakkiyachelvi M, Elakkiya E, Fathima S. Acceptability and awareness of intrauterine contraceptive device among reproductive age women. Int $\mathrm{J}$ Community Med Public Health 2021;8:5075-8. 